\title{
Methotrexate in rheumatoid arthritis: a prospective study in Israeli patients with immunogenetic correlations
}

MOSHE TISHLER,' DAN CASPI, TAL O ROSENBACH, ${ }^{1}$ BENO FISHEL, ${ }^{1} \vec{\circ}$ IRENA WIGLER, ${ }^{2}$ RAFAEL SEGAL, ${ }^{2}$ EPHRAM GAZIT, ${ }^{2}$ AND MICHAEL YARON

From the 'Department of Rheumatology, Ichilov Hospital, Tel Aviv Medical Center, Tel Aviv University $\frac{\varrho_{0}^{2}}{2}$

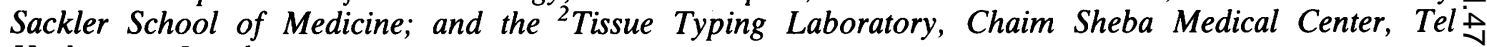
Hashomer, Israel

SUMMARY In a prospective open study 44 Israeli patients with rheumatoid arthritis were treated $\stackrel{\circ}{\rightarrow}$ with weekly low dose methotrexate (MTX) for up to 36 months. Nine patients withdrew from the $\vec{\square}$ study: six because of side effects and three due to inefficacy. One patient died of septicaemiac following septic arthritis. Significant improvement, graded by Ritchie articular index, grip $\stackrel{5}{\sim}$ strength, physician's global assessment, erythrocyte sedimentation rate (ESR), and platelet $\vec{\bullet}$ counts, was noticed in response to treatment. Seronegative patients had a better clinical $\infty_{\infty}^{\infty}$ response. Transient gastrointestinal symptoms were common and correlated with increases of serum aspartate transaminase (AST). HLA-DR1 and DR7 were significantly associated with increased serum AST concentrations.

Key words: HLA antigens.

The use of methotrexate (MTX), a folic acid antagonist, as an effective agent suppressing synovitis in rheumatoid arthritis (RA) was first reported by Gubner et al in 1951. ' The drug was not in use for many years in patients with RA, however, although there has been extensive experience with MTX in the treatment of psoriasis. ${ }^{2}$ Clinical studies in recent years established its efficacy in the treatment of patients with RA not responding to other drugs. ${ }^{4-9}$ Although rapid therapeutic benefit was observed in all short term studies, ${ }^{4-7}$ the longer term effectiveness of MTX has been shown only in a few detailed reports. ${ }^{89}$ We conducted an open prospective study to $(a)$ assess the short and medium term efficacy of MTX in our patients with RA, (b) study the various side effects and their interrelationships, and $(c)$ search for a genetic predisposition to the therapeutic response or side effects of MTX in Israeli patients, who differ immunogenetically from other populations.

Accepted for publication 8 January 1988.

Correspondence to Dr Moshe Tishler. Department of Rheumatology, Ichilov Hospital, $64239 \mathrm{Tel}$ Aviv, Isracl.

\section{Patients and methods}

PATIENTS
Forty four patients with definite or classical $\mathrm{RA}_{\overline{0}}^{\frac{0}{0}}$ fulfilling the criteria of the American Rheumatism Association (ARA) entered the study. Thirty nined patients $(89 \%)$ had received gold salt treatment, 293 $(66 \%)$ penicillamine, $17(39 \%)$ azathioprine, and 14 응 (32\%) hydroxychloroquine. All drugs had been discontinued because of ineffectiveness or toxicity $\frac{D}{2}$

Treatment with disease modifying drugs was stopped for at least two months before entering the $\mathscr{N}$ study. Other criteria for entry were the presence of 0 active disease defined by at least three of theN following criteria: three or more swollen joints, six ${ }_{\sigma}^{\omega}$ or more tender joints, 45 minutes or more of morning stiffness, and an erythrocyte sedimentation rate (Westergren) exceeding $28 \mathrm{~mm}$ an hour.

\section{STUDY DESIGN}

This prospective study was started in 1983 and conducted until 1987. Individual patients entered $\frac{?}{\mathbb{P}}$ the study gradually, thus the duration of treatment 0 was not equal in all the patients. 
Patients were evaluated before the start of treatment and during the study period by the same physician. All patients were seen every three weeks for evaluation of toxicity, adjustment of drug doses, and laboratory assessment. Prednisone treatment, kept stable for at least a month before study entry, was allowed throughout the trial and was tapered according to clinical improvement.

All patients were treated initially with $7.5 \mathrm{mg}$ MTX administered intravenously in the first week. Doses were increased up to $15 \mathrm{mg}$ a week according to clinical response. Elderly patients ( $>65$ years old) and patients with a creatinine clearance test of less than $60-80 \mathrm{ml} / \mathrm{min}$ did not receive doses exceeding $10 \mathrm{mg}$ a week.

Excluded from the study were patients with a history of cancer, liver or renal disease, white blood cell counts of $<3.5 \times 10^{9} / 1$, or platelet counts $<150 \times 10^{9} / 1$.

When adverse effects occurred the MTX dosage was lowered by $2.5 \mathrm{mg}$ a week until they disappeared or became tolerable. After reaching a favourable clinical response, patients were switched to a regimen of alternate intravenous and oral weekly MTX treatment.

CLINICAL ASSESSMENT

Clinical evaluation was recorded at the baseline visit and every three months thereafter and consisted of

Table 1 Characteristics of 44 patients with RA entering the methotrexate treatment study

\begin{tabular}{lc}
\hline Age (years) & $*$ \\
Disease duration (years)* & $60 \cdot 2$ \\
Male/female & $10 \cdot 5$ \\
RF† positive & $3 / 41$ \\
ANF† positive & 33 \\
Sjögren's syndrome & 11 \\
\end{tabular}

*Mean value shown.

$\dagger \mathrm{RF}=$ rheumatoid factor; $\mathrm{ANF}=$ antinuclear factor. the following: duration of morning stiffness in minutes; Ritchie articular index; mean grip strength $(\mathrm{mmHg})$ for both hands; physician's global assessment of pain and disease activity, graded as 1 (severe), 2 (moderate), 3 (mild), 4 (asymptomatic).

\section{LABORATORY ASSESSMENT}

Laboratory tests for potential drug toxicity were obtained at baseline and every week during the first three months of MTX treatment and then every two to three weeks according to drug regimen. These tests included a complete blood count (including platelets), serum aspartate transaminase (serum AST), alkaline phosphatase, creatinine, and erythrocyte sedimentation rate (Westergren). Urine analysis, serum albumin concentrations, and latex rheumatoid factor results were obtained every six months. Increases of serum AST to twice that of normal levels, a decrease in the white cell count to $<3.5 \times 10^{9} / 1$, or a decrease in the platelet count to $<150 \times 10^{9} /$ l were considered sufficient cause to stop MTX until these values returned to normal, when treatment was resumed at a lower dose.

HLA TYPING

HLA-A, B, C antigens were determined by the microlymphocytotoxicity technique. ${ }^{10}$ HLA-DR typing was performed on B cell enriched lymphocytes by extended incubation cytotoxicity testing. " The prevalence of HLA antigens was compared with that of healthy controls typed by the same laboratory.

STATISTICAL ANALYSIS

Statistical comparisons were made using the repeated measures analysis of the variance. ${ }^{12}$ The Fisher exact test was used in the analysis of HLA data.

\section{Results}

Table 1 shows the patients' characteristics on entry

Table 2 Laboratory and clinical variables in patients during MTX treatment*

\begin{tabular}{|c|c|c|c|c|c|c|c|}
\hline Parameter & $\begin{array}{l}\text { Baseline } \\
(n=44)\end{array}$ & $\begin{array}{l}3 \text { Months } \\
(n=43)\end{array}$ & $\begin{array}{l}6 \text { Months } \\
(n=29)\end{array}$ & $\begin{array}{l}12 \text { Months } \\
(n=I 7)\end{array}$ & $\begin{array}{l}\text { I8 Months } \\
(n=12)\end{array}$ & $\begin{array}{l}24 \text { Months } \\
(n=6)\end{array}$ & $\begin{array}{l}36 \text { Months } \\
(n=6)\end{array}$ \\
\hline $\mathrm{ESR}+(\mathrm{mm} / \mathrm{h})$ & $64 \cdot 3(3 \cdot 6)$ & $44 \cdot 9(3 \cdot 19)$ & $41 \cdot 9(4 \cdot 05)$ & $49 \cdot 2(5 \cdot 76)$ & $48 \cdot 5(5 \cdot 1)$ & $49 \cdot 8(11 \cdot 9)$ & $45 \cdot 5(7 \cdot 11)$ \\
\hline $\mathrm{Hb}+(\mathrm{g} / \mathrm{l})$ & $114(2)$ & $115(1)$ & $119(2)$ & $111(2)$ & $112(51)$ & $117(5)$ & $113(3)$ \\
\hline Platclets $\left(\times 10^{9} / 1\right)$ & $399(22)$ & $352(16)$ & $352(18)$ & $354(24)$ & $355(30)$ & $359(40)$ & $348(23)$ \\
\hline WBC $+\left(\times 10^{y} / 1\right)$ & $8(0 \cdot 26)$ & $7 \cdot 9(0 \cdot 26)$ & $7 \cdot 6(0 \cdot 33)$ & $7 \cdot 5(() \cdot 47)$ & $7 \cdot 4(0 \cdot 5)$ & $7 \cdot 2(0 \cdot() 9)$ & $7 \cdot 4(0 \cdot() 8)$ \\
\hline Ritchic index & $35(2)$ & $23 \cdot 5(2)$ & $19.4(2.4)$ & $20 \cdot 6(2 \cdot 9)$ & $20(3 \cdot 1)$ & $16 \cdot 8(4 \cdot 8)$ & $15 \cdot 6(4 \cdot 8)$ \\
\hline Grip strength (mmHg) & $64 \cdot 7(7 \cdot 2)$ & $74(9)$ & $71 \cdot 7(7 \cdot 4)$ & $76 \cdot 8(15)$ & $75 \cdot 4(22)$ & $76 \cdot 2(16)$ & $82(22 \cdot 6)$ \\
\hline Clinical assessment & $1 \cdot 8(0 \cdot 1)$ & $2 \cdot 8(0 \cdot 1)$ & $2 \cdot 8(0 \cdot 2)$ & $2 \cdot 75(0 \cdot 2)$ & $2 \cdot 8(0 \cdot 2)$ & $2 \cdot 9(0 \cdot 1)$ & $3 \cdot()(0 \cdot 2)$ \\
\hline
\end{tabular}

*Values are mean (SE).

$+E S R=$ crythrocyte sedimentation ratc; $\mathrm{Hb}=$ hacmoglobin: $\mathrm{WBC}=$ white blood cell count. 
into the study. Their mean age was $60 \cdot 2$ years (range $30-87$ ) and mean disease duration 10.5 years (range 1-33). All patients received an average weekly dose of $12.5 \mathrm{mg}$ (range $7 \cdot 5-15$ ) intravenous or oral MTX and the mean duration of treatment was 11 months (range 3-36).

Treatment was stopped in 10 patients: one patient developed septic arthritis and later died, one experienced severe allergic reaction, five discontinued MTX owing to nausea and vertigo, and there was a lack of effect in three patients.

\section{CLINICAL AND LABORATORY RESPONSE}

Table 2 presents the clinical and laboratory findings of patients in each assessment. Clinical improvement scored by the Ritchie articular index, grip strength, and physician's evaluation of global disease was clearly evident. Therapeutic effect was noticed within the first six weeks, though individual patients experienced subjective benefit as early as? two weeks. Improvement continued until a plateat was reached at six months. The beneficial effect was noted in the whole group of patients, including those who had to be withdrawn because of side effects $\frac{\bar{c}}{\bar{n}}$ When the small group of patients who had startech MTX early enough to complete 36 months of treatment was analysed further improvement wass observed (Fig. 1). During the first six months of MTX treatment the mean Ritchie articular index decreased from 35 to $19 \cdot 4$, mean grip strengttw increased from $64.7 \mathrm{mmHg}$ to $71.7 \mathrm{mmHg}$, and the्छो physician's evaluation of global disease improve from 1.8 to $2.8(\mathrm{p}<0.002$ for all parameters). I

The ESR decreased from an average of $64.3 \mathrm{~mm} / \mathrm{lpo}$ at baseline to $41.9 \mathrm{~mm} / \mathrm{h}$ at six months of treatmenf $(\mathrm{p}<0.0001)$, but rose again to $49 \mathrm{~mm} / \mathrm{h}$ at 12 and $24^{\mathrm{p}}$ months. Platelet counts decreased from $399 \times 10^{9} / 1$ ab baseline to $352 \times 10^{9} / 1$ at six months $(\mathrm{p}=0.0086)$ and
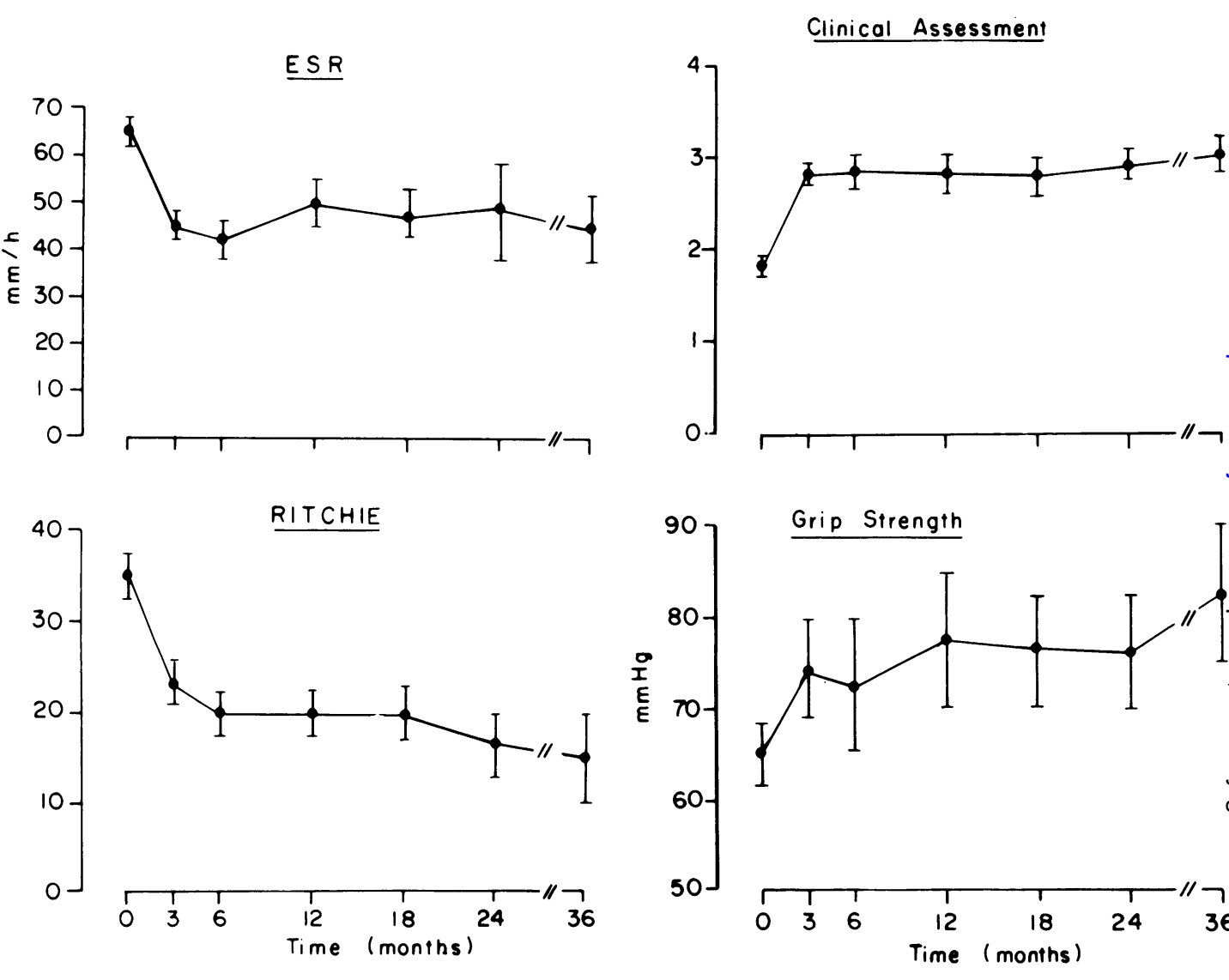

Fig. 1 Clinical and laboratory parameters (mean (SE)) in patients taking methotrexate during 36 months of treatment. 
remained steady throughout 36 months. Leucocyte counts and haemoglobin concentrations were not significantly changed during the study.

No patient achieved complete remission according to the ARA criteria. 13

Clinical parameters indicated that response to MTX was better in seronegative than in seropositive patients $(\mathrm{p}<0.05)$ (Figs $2 \mathrm{a}$ and $\mathrm{b})$. No difference in laboratory parameters was observed between the two groups, however.

TOXICITY

Adverse reactions were common, though usually mild, and required discontinuation of treatment in only seven patients.

Two patients suffered serious side effects. One died from sepsis following septic arthritis of a prosthetic hip joint after 10) weeks of treatment and a total dose of $90 \mathrm{mg}$ MTX. The pathogen could not

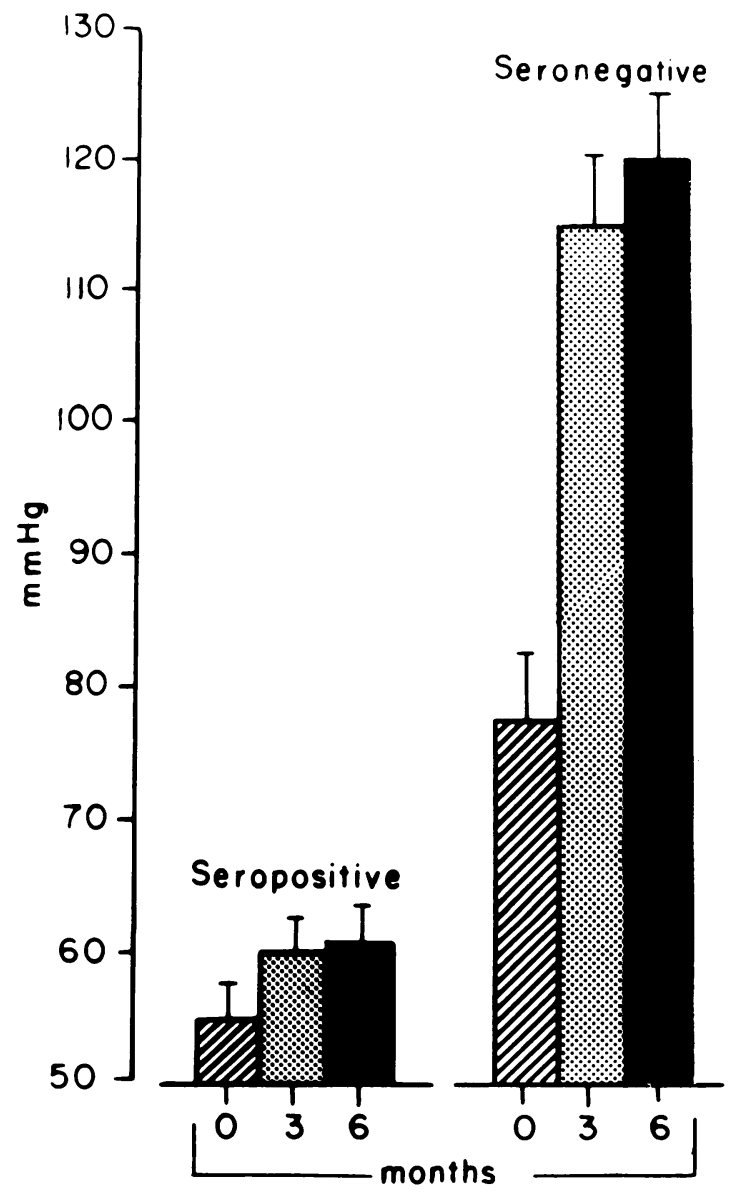

Fig. 2a

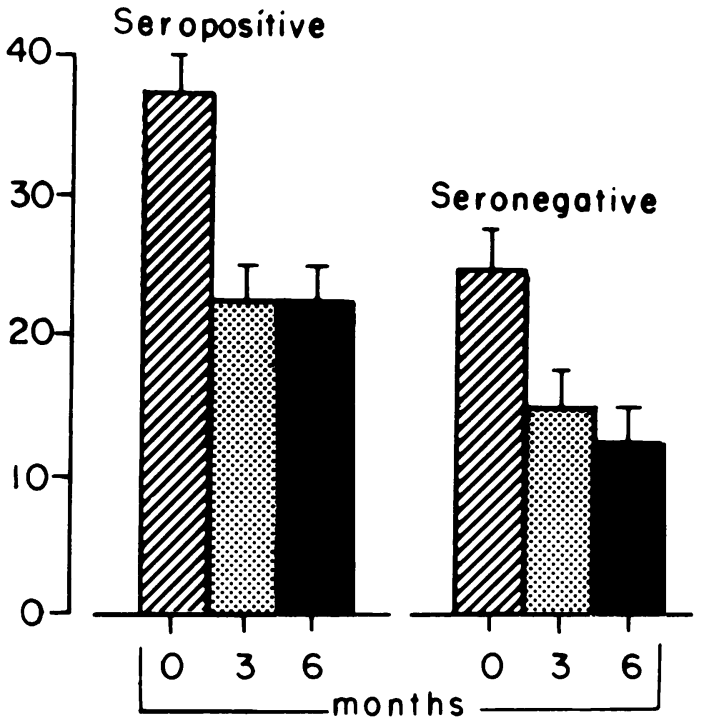

Fig. 2b

Fig. 2 Relative improvement in clinical parameters of seronegative and seropositive patients taking methotrexate. (a) Grip strength; (b) Ritchie articular index $(p<0.05$ for both values).

be identified. A second patient developed a severe allergic rash and urticaria after 18 weeks of treatment. Gastrointestinal toxicity, manifested by nausea and abdominal discomfort. was common (21 of 44 patients $(48 \%))$. but in only four patients was it the cause for termination of treatment. In 17 $(80 \%)$ of the 21 patients these symptoms began in the first three months of treatment. Vertigo and lightheadedness were reported by six patients $(14 \%)$ but required cessation of treatment in only one case. Transient leucopenia was observed in two patients and thrombocytopenia in one; both resolved after lowering the MTX dosage. Two patients had an increase in the number of rheumatoid nodules during treatment, but when treatment was stopped for other causes this phenomenon reversed.

Transient increase of transaminase levels was seen in 15 patients $(34 \%)$, mostly between the second and the seventh months of treatment. In only five of the 15 patients $(33 \%)$ was there a twofold increase in transaminase concentrations, which returned to normal after withholding MTX treatment for a week and reinstituting it at a lower dosage.

Analysis of the interrelationships of the various side effects to MTX showed a marked association between the existence of gastrointestinal symptoms and an increase of serum AST concentrations $(p=0 \cdot 0)(06)$, while the association between gastroin- 
Table 3 Prevalence of HLA-DR antigens in MTX treated patients with or without increases in serum aspartate transaminase (AST)

\begin{tabular}{llll}
\hline $\begin{array}{l}H L A \\
\text { antigen }\end{array}$ & $\begin{array}{l}\text { Prevalence of } \\
\text { ALA-DR antigens in: }\end{array}$ & \\
\cline { 2 - 4 } & $\begin{array}{l}\text { Patients with } \\
\text { increase in } \\
\text { serum } A S T\end{array}$ & $\begin{array}{l}\text { Patients without } \\
\text { increase in } \\
\text { serum } A S T\end{array}$ & $\begin{array}{l}\text { Normal } \\
\text { controls } \\
(\%)\end{array}$ \\
& $(\%)$ & $(\%)$ & \\
\hline DR1 & $40 \cdot 0^{*}$ & $15 \cdot 3$ & $15 \cdot 8$ \\
DR4 & $33 \cdot 3$ & $44 \cdot 1$ & $38 \cdot 3$ \\
DR5 & $33 \cdot 3$ & $37 \cdot 3$ & $42 \cdot 5$ \\
DR6 & $20 \cdot 0$ & $22 \cdot 0$ & $18 \cdot 0$ \\
DR7 & $33 \cdot 3+$ & $8 \cdot 5$ & $11 \cdot 1$ \\
\hline
\end{tabular}

${ }^{*} \mathrm{p}<0.05 ; \mathrm{tp}<0 \cdot 02$.

testinal and central nervous system symptoms was less significant $(p=0 \cdot 055)$.

PREDNISONE DOSAGE

Twenty five patients $(57 \%)$ required prednisone treatment before the start of the study, with a mean dose of $10.3 \mathrm{mg} /$ day (range 5-25). In the course of the study 10 patients were completely withdrawn from steroids and the mean prednisone dosage in the others decreased to $6.5 \mathrm{mg} /$ day $(\mathrm{p}<0 \cdot 05)$.

ASSOCIATION OF HLA ANTIGENS AND THE

CLINICAL AND LABORATORY FINDINGS

The prevalence of HLA-A, B, C, and DR antigens of our patients with RA showed no significant difference from that of the normal Israeli control population (data not shown). Nor was there any association of the antigens with clinical or laboratory parameters indicating drug efficacy. An increase of serum AST concentrations, however, after MTX treatment was observed in HLA-DR7 or DR1 positive patients $(p<0.02$ and $p<0.05$ respectively) (Table 3).

\section{Discussion}

This prospective study confirms other observations on the beneficial effect of MTX in patients with RA. We have shown that the MTX response is characterised by a quick onset (five to six weeks) and a continuous improvement until six months, at which time a plateau is reached. Clinical parameters such as Ritchie articular index, grip strength, and clinical assessment, as well as laboratory tests such as ESR and platelet counts, showed a significant improvement $(p<0.01)$ during the first year of treatment. Although further improvement was observed during the following two years of treatment, the small number of patients that reached 36 months of treatment does not allow definite statistical conclu- $-\frac{\infty}{?}$ sions to be drawn. A novel observation is the $\overrightarrow{\vec{F}}$ significant difference in clinical response to MTX between seronegative and seropositive patients. 등 This could be explained by a better anatomical stage $\overline{\bar{m}}$ of the former group.

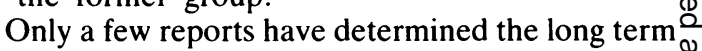
efficacy of MTX. The duration of the favourable clinical response ranged from three years ${ }^{8}$ up to $15 \overrightarrow{0}$ years in one study. ${ }^{9}$ It should be emphasised that $\overrightarrow{ }$ MTX was employed in patients with advanced disease, in whom other second line drugs had failed. Despite that fact, approximately $50 \%$ of patients? with RA had benefited from the drug and $7-20 \%=$ achieved complete remission. ${ }^{89}$ In our study,,$\infty$ although a marked improvement was noted in many: patients, no true articular remission, as defined by the ARA, was reached.

Clinical side effects, though common, were $\vec{\longrightarrow}$ usually mild and tolerable and responded to dosage reduction. Gastrointestinal toxicity was observed in $48 \%$ of patients and vertigo in $14 \%$, as in earlier studies. $^{4-914}$ Only one patient experienced severe $\vec{\infty}_{\infty}$ toxicity manifested by allergic reaction. One patient died of sepsis during treatment.

Liver fibrosis was reported in psoriatic patients receiving prolonged MTX treatment but not in patients with RA. ${ }^{8}{ }^{15}$ Furthermore, no correlation was found between an increase of transaminase $\stackrel{\mathbb{Q}}{\triangle}$ concentrations and hepatic changes in serial liver $\overrightarrow{\vec{A}}$ biopsy specimens. ${ }^{8}$ As in previous studies ${ }^{4-9} 14$ we also found frequent increases in transaminase concentrations, which decreased after dosage reduc $=0$ tion. Interestingly, in our patients gastrointestinal symptoms had a strong correlation with serum ASTo increases $(p=0.0006)$ and usually appeared early in the course of treatment, predicting liver function abnormalities. The association between raisedô serum AST and HLA-DR7 and DR1 is also unique and has not been reported previously. ${ }^{5814}$ This mays be explained by the different genetic background of the Israeli population in whom RA is associated? with DR1 and not DR4. ${ }^{16}$ Yet, as in othern reports, ${ }^{58}$ we could not find in our study group any? HLA antigen predictive of a favourable response to MTX.

The optimal dose and route of MTX administra-O tion in patients with RA has been a matter of debate. It has been administered intravenously orally, and intramuscularly with a similar rate of success. ${ }^{4-9}$ There is no clear evidence that any one 0 way has an advantage over the others. We use MTX. intravenously in the first weeks of treatment and? then switch to alternate oral and intravenous treatment.

The effect of MTX on acute phase reactants such 
as ESR and platelet counts and the profound clinical response places the drug together with other disease modifying drugs and raises the question of its earlier use in RA. Recently, MTX was shown to improve erosive changes in seven of 11 patients over a two year period, ${ }^{8}$ a fact that further supports its use in the earlier stages.

In conclusion, the results of this study suggest that methotrexate is an effective drug in the treatment of severe rheumatoid arthritis over a period of six to 36 months. Yet, the exact place of methotrexate among second line drugs has to be determined.

We are indebted to Mrs Pearl Lylos, statistical laboratory. department of mathematics, Tel Aviv University, for the excellent statistical analysis, to Mrs Ofelia Cohen-Avishai for HLA typing. and to Miss Shani Hanft for preparing the manuscript.

\section{References}

1 Gubner R, August S, Ginzberg V. Therapeutic suppression of tissue reactivity. Il. Effect of aminopterin in rheumatoid arthritis and psoriasis. Am J Med Sci 1951: 221: 176-82.

2 Kersley G D. Amethopterin (methotrexate) in connective tissuc diseases-psoriasis and polyarthritis. Ann Rheum Dis 1968: 27: 64-6.

3 Nyfors A. Methotrexate therapy of psoriasis. Dan Med Bull 1980; 27: 74-96.

4 Thompson R N. Watts C. Edelman J. Esdailc J, Russel S. A controlled two-center trial of parenteral methotrexate therapy for refractory rhcumatoid arthitis. J Rheumatol 1984: 11: 76()-3.

5 Weinblatt M E. Coblyn J S. Fox D A. et al. Efficacy of low dose methotrexate in rheumatoid arthritis. $N$ Engl J Med 1985; 312: 818-22.

6 Andersen P A. West S G. O`Dell J R. Via C S. Claypool R G. Kotzin B L. Weckly pulse methotrexate in rheumatoid arthritis. Ann Intern Med 1985: 103: 489-96.

7 Williams H J, Willkins R F. Samuelson C P. et al. Comparison of low dose oral pulse methotrexate and placebo in the treatment of rheumatoid arthritis. Arthritis Rheum 1985: 28: 721-30.

8 Kremer J M. Lee J K. The safety and efficacy of the use of methotrexate in long term therapy for rheumatoid arthritis. Arthritis Rheum 1986; 29: 822-31.

9 Weinstein A, Marlow S. Korn J. Farduhar F. Low-dose methotrexate treatment of rheumatoid arthritis. Am J Med 1985; 79: 331-7.

10 Terasaki P I, Bernaco D. Park M S. Ozturk G. Iwaki Y Microdroplet testing for HLA-A-B-C and DR antigens. Am J Clin Pathol 1978; 69: 103-20.

11 Mittal K K. Mickey M R. Signal D P. Terasaki P I. Serotyping for demotransplantation. Refinement of microdroplet lymphocytc cytotoxicity test. Transplantation 1968; 6: 913-27.

12 Dixon W J. Biomedical software P-series. California: University of California Press. 1983.

13 Pinals R S. Masi A T. Ransen R A. the subcommittee for criteria of remission in rheumatoid arthritis of the American Rheumatism Association diagnostic and therapcutic criteria committee. Preliminary criteria for clinical remission in rheumatoid arthritis. Arthritis Rheum 1981; 24: 1308-15.

14 Gispen J G, Alarcon G S. Johnson J J, Acton R T. Barger B D, Koopman W J. Toxicity to methotrexate in rheumatoid arthritis. J Rheumatol 1987: 14: 74-9.

15 Roenigk H H. Auerbach R. Maibach H I. Weinstein G D. Methotrexate guidelines revised. J Am Acad Dermatol 1982; 6: 145-55.

16 Schiff B. Mizrahi Y. Orgad S, Yaron M. Gazit E. Association of HLA-Aw31 and HLA-DR1 with adult rheumatoid arthritis. Ann Rheum Dis 1982: 41: 403-4. 